\title{
Socio-Economic Effects of HIV/AIDS on Households with People Living With HIV/AIDS in Northern Nigeria
}

\author{
Suleiman Mohammed Saeed ${ }^{\mathrm{a}}$, Dusadee Ayuwat ${ }^{\mathrm{b}}$ \\ ${ }^{a}$ Khon Kaen University, Thailand Federal University, Gashua, Yobe State, Nigeria \\ ${ }^{\mathrm{b}}$ Khon Kaen University, Thailand \\ amohammedsaeedsuleiman@ fugashua.edu.ng, bdusayu@kku.ac.th \\ b* Corresponding Author email id:dusayu@kku.ac.th
}

Article History: Received: 10 November 2020; Revised 12 January 2021 Accepted: 27 January 2021; Published online: 5 April 2021

\begin{abstract}
The purpose of this paper is to review the socio-economic effects of Human Immunodeficiency Virus (HIV) and Acquired Immune Deficiency Syndrome (AIDS) on households with People Living with HIV/AIDS (PLWHA) in Northern Nigeria. The pandemic is devastating and constitutes a serious threat to the socio-economic development of infected, affected, and society at large. This study was qualitative in nature, thus it utilized in-depth interviews to pull together information from the 39 key informants as its method. It is observed that HIV/AIDS occurrence rate has led to poor health, loss of jobs, and a high rate of labour reduction in all sectors, and this has contributed to the tremendous decline of the economy. This study discovered that increased expenses of households with PLWHA on financing funerals, healthcare, and other medical expenditures with decreased investment. Children emerging as head of the households and tasks of caring for orphans are increasingly inconsistent with many other studies. The pandemic has been a serious threat to the social and economic interests and survival of the households with PLWHA and their members. Many lives are lost due to the pandemic. The worst affected group is young people in their productive ages and by implication affects the socio-economic development of PLWHA, their households, and society at large. Thus, households with PLWHA experience numerous forms of stigma and prejudice together with human rights abuse that is detrimental to the total well-being of PLWHA. The dimensions of the stigma can be classified as internalized, community, and social-based. The patterns of managing the challenges of HIV/AIDS-related stigma adopted from the experience of households with PLWHA adopted include isolation, non-disclosure, and loss of follow-up as well as migration. The paper suggested that the government should come up with policies that can take care and support the socioeconomic activities of households with PLWHA and also need to introduce policies and procedures for the reduction of stigma and discrimination against households with PLWHA and its members living with the epidemic. Households with PLWHA need to be assisted with medication subsidies to reduce medical expenses and stress on the households' capitals among other recommendations..
\end{abstract}

Keywords: HIV/AIDS, Household, Northern Nigeria, PLWHA, Socio-Economic

\section{Introduction}

Households with People Living With HIV/AIDS (PLWHA) are expected to fine-tune their livelihood activities as observed by Ayuwat and Chamarattana (2014) in order for households to adjust themselves to cope with numerous challenges facing them such as work allocation within households and managing debts which are common to households with PLWHA. Similarly, it is observed that to ameliorate the shock and stress of households with PLWHA, it is significant in tackling the HIV/AIDS epidemic and associated socioeconomic challenges which are essentially overturning the descending spiral of livelihood deprivation and boost the affected households towards higher earnings as well as contributing to the sustainable development of the affected communities (Frantz \& Murenzi, 2014; The Joint United Nations Programme on HIV/AIDS [UNAIDS], 2016; World Health Organization [WHO], 2015).

The economic status of households with PLWHA in Northern Nigeria, in particular, is observed to be highly pathetic because previous studies show that the economic status of households with PLWHA in relation to their lifestyles has significant implications for HIV/AIDS responses as poverty increases weakness to HIV with negative consequences on the ability of the households with PLWHA to appropriately seek for or adhere optionally to the treatment of their victims (John et.al. 2013; Mwai et.al. 2013; Smith, 2013).

It is observed that the annual estimated healthcare expense for PLWHA in Nigeria is \$58 per capita; while \$7 for HIV negative persons causing inability of infected and affected households with PLWHA to meet up with their socio-economic demands in the country and adversely consequences since the majority of the individual living with the epidemic are in their productive age and households continued to incur increased costs on livelihoods compared to their counterpart whose households members are having the negative status of the epidemic. In the 
same way, as regards the state of affairs of the livelihoods of households with PLWHA in Northern Nigeria, it is noticed that owing to their health challenges or HIV/AIDS status, per capita income losses were estimated at \$116 as compared to $\$ 21$ for the negative individuals per household (Folayan et.al. 2014; Galadanchi et.al. 2014; Gardener \& Young, 2014, Song, 2013).

The population of PLWHA globally has levelled off at 37 million. Nigeria as the most heavily populated nation in Africa continent remains a burdened nation with about 3.6 million people living with the epidemic with the most threatened groups comprising commercial sex workers together with their customers, intravenous drug addicts, homosexuals, and the mobile population groups like long-distance drivers along with uniformed services personnel and by inference Nigeria is the second foremost nation with the encumber of HIV disease in the globe with contributions of $9 \%$ of the people living with HIV presently, another $10 \%$ of new infections while having $14 \%$ of HIV related deaths in the world. Furthermore, the worst affected group are young people aged 15-24 years and female, it is also believed that three out of four new infections are among women and twice likely the rate of women living with the epidemic than men (National HIV/AIDS Strategic Framework [NHASF], 2017-2021; UNAIDS, 2017; WHO, 2016). Thus, the consequences of HIV/AIDS on Nigerian households with PLWHA are apparent and having policy relevancies, however, very small empirical work is known in this area which is of concern in this study.

It is important to point out that households with PLWHA go through severe hardship due to the sickness or their status and they usually stand the trouble of taking care of any member of the household living with the epidemic, whereas also being accountable for seeking household food and income. It is observed that the majority of these households face the challenges of critical resources for socio-economic survival due to HIV/AIDS as noted by Fatusi et.al. (2016), Levien (2015) reveals that empirical evidence has shown that, when large expenditure goes in the direction of treatment and funeral, care giving tasks increase, income depreciates due to precipitate mortality and morbidity among the younger adult wage earners, households may be incapable to cope with the financial shock as well as stress.

It is pertinent to mention that HIV/AIDS pandemic affects human and material resources globally particularly in Africa, Asia, and Latin America, and its implication having a direct severe consequence on the social and economic. Thus, the objective of this study is to examine the socio-economic effects of HIV/AIDS on households with PLWHA in Northern Nigeria with a focus on the social and economic consequences on households.

\section{HIV/AIDS Prevalence}

The impact of HIV/AIDS cannot be underscored since it was first recorded publicly in the year 1981 while according to NHASF (2017-2021), UNAIDS (2017), WHO (2016) that the population of PLWHA globally has levelled off at 37 million and Nigeria as the most heavily populated nation in Africa continent remains a burdened nation with about 3.6 million PLWHA with the most threatened groups comprising commercial sex workers together with their customers, intravenous drug addicts, homosexuals and mobile population groups like longdistance drivers along with uniformed services personnel and by inference Nigeria is the second foremost nation with the encumber of HIV disease in the globe with contributions of $9 \%$ of the PLWHA presently, another $10 \%$ of new infections while having $14 \%$ of HIV/AIDS interrelated deaths in the universe. Furthermore, the most horrible affected group are the younger folks between 15-24 years and addition female, it is also believed that three out of four new infections are among women and twice likely the rate of women living with the epidemic than men (NHASF, 2017-2021; UNAIDS, 2017).

To this end, it is pertinent to observe that from the time when the first case of the pandemic was diagnosed in the year 1986 in Nigeria, the occurrence pace have unobstructed increases from 1.8 million in 1992 to 3.6 million in 2017, which by implication HIV/AIDS is no more health issues but a multifaceted disaster affecting every section of our daily endeavour. While changes in the social structure in Nigeria such as changing in the household system due to migration, migration due to industrialization leading to urbanization, urbanization due to migration for white-collar jobs leading to changes in socialization process such as peer group influences of going to clubs, engaging in alcoholism, drug addiction, prostitution, having multiple sex partners among others are obviously contributing factors to the prevalence rate making the epidemic more than public health issues but an epidemic that needs a multidisciplinary approach.

Nigeria's initial official case of AIDS was acknowledged publicly in 1986 and the country has the second largest cases of the pandemic in the human race (NACA, 2015; NHASF, 2017-2021). It is worth noting that 60\% of the new cases of the HIV/AIDS interrelated infectivity are in Western and Central Africa, in Nigeria, simultaneously with South Africa and Uganda, these countries record nearly the larger parts of all new infections in Sub-Saharan Africa yearly, notwithstanding the recording of 35\% decrease in new infectivity between 2005 2013 (UNAIDS, 2014; UNAIDS, 2016). From all indications, it is obvious that Nigeria as a nation has the second 
largest cases of the HIV/AIDS pandemic in the universe and also with one of the largest new infectivity paces in Sub-Saharan Africa.

Data available shows that the epidemic known as HIV/AIDS is still high with the highest incidence rate in Nigeria's Southern States (recognized as South-South Zone), and stands at 5.5\%, it is diminutive in the South East (South East Zone) with an occurrence rate of $1.8 \%$, while the data further revealed that the remaining Zones prevalence rates stand at Central Zone 3.4\%, North East Zone 3.5\%, North West 3.2\% and South West 2.8\% respectively and there are higher occurrence rates of HIV/AIDS in rural areas (4\%) than in the urban areas (3\%) (NACA, 2015; NHASF, 2017-2021; UNAIDS, 2017). The geographic divergences in the dynamics of the pandemic rate put forward from the data available indicate the pressure and aid of the diverse high-risk behaviours differ relatively significance in the diverse communities and geographical settings within the nation and it has repercussions on the livelihoods of households with PLWHA.

It is imperative to note that from the available literature the forces behind the HIV/AIDS pandemic in Nigeria comprise, low-risk perception, numerous coexisting cohorts, casual transactional and intergenerational sex, poor services for sexually transmitted infections (STIs), and poor quality of health services, gender disparity, poverty, as well as HIV/AIDS interrelated stigma and discrimination equally aid the broaden of the pandemic (NACA, 2015). Thus, it is observed that most of the PLWHA in Northern Nigeria are vulnerable and this can push them to the margins of the society with consequences on livelihoods.

\section{Methods}

This study adopts a qualitative procedural and explicitly phenomenological in nature and employed in-depth interviews, participatory and non-participatory observations as research tools. The interview period of conducting the fieldwork was from August to November 2019 and twenty-one households with PLWHA in Northern Nigeria were utilized as the qualified target. This study utilized Northern Nigeria which is one of the regions with the highest prevalence rate of PLWHA and it is also a region with various diverse people. It is essential to declare that many households in the research settings are into subsistence agriculture and engage in mixed farming systems and commercial farming also. The main food crops in the study sites are maize, sweet potatoes, beans, sugar canes, millets, and vegetables among other crops. Likewise, several households engage in trading, driving, livestock, fishing, food vendors' government, and seasonal jobs among others as means of sustaining their livelihoods.

Thus, semi-structured and in-depth were used to conduct interviews with 39 key informants comprising KADSACA officials, health workers, and volunteers working in the areas of care and support for PLWHA as well as the village heads, imams, and pastors who are the custodians of the socio-cultural beliefs of the people in the society as the key informants for the first group at the community level. Also semi-structured in-depth interviews were carried out through the means of face-to-face interactions with the participants (households with PLWHA) to produce the accounts of the knowledge or experiences of those households living with and managing PLWHA as the key informants for the second group at the households level. The researcher took notes and recorded activities that took place for the purpose of this research only. Also, participant and nonparticipant observation methods were employed, especially the non-participant observation method because it was not possible to take part in all the participatory observation methods. Thus, for the purpose of analysis, the data collected for this research were done through content analysis. Table 1 below depicts the summary of the key informants for this study:

Table 1: Summary of the Key Informants of the Study

\begin{tabular}{|c|c|c|c|c|c|}
\hline \multirow[t]{3}{*}{ No of Group } & \multicolumn{4}{|c|}{ Area } & \\
\hline & \multirow[t]{2}{*}{ Position of Key Informant } & \multicolumn{3}{|l|}{ Village } & \multirow[t]{2}{*}{$\mathbf{N}$} \\
\hline & & Barnawa & Kakuri Gwari & Television & \\
\hline \multirow[t]{6}{*}{$1^{\text {st }}$} & KADSACA Official & 1 & 1 & 1 & 3 \\
\hline & Health Worker & 1 & 1 & 1 & 3 \\
\hline & Volunteer & 1 & 1 & 1 & 3 \\
\hline & Village Head & 1 & 1 & 1 & 3 \\
\hline & Imam & 1 & 1 & 1 & 3 \\
\hline & Pastor & 1 & 1 & 1 & 3 \\
\hline $2^{\text {nd }}$ & Households with PLWHA & 7 & 7 & 7 & 21 \\
\hline
\end{tabular}


Source: Qualitative Study, 2019

\section{Social Effects}

The social repercussion of HIV/AIDS revolves centrally around stigmatization and discrimination of the infected and affected in the society. Stigma can be described as a powerful social process to underestimate people based on real or perceived differences such as gender, age, sexual orientation, behaviour, ethnicity, or belief. Link and Phelan (2001) and Parker and Aggelton (2003) put forward that the current effort in the disciplines of sociology and anthropology has widened previous notions of stigma to include the structural circumstances that add to stereotyping. While Goffman (1963) described stigma as an undesirable or a discrediting family attribute anyone possesses.

HIV/AIDS-related stigma is central to the prejudice and discrimination directed to households with PLWHA and their infected members. Households with PLWHA from experience described stigma as the astonishing or anticipated fear of how other people respond to households with PLWHA. It is observed, those households with PLWHA and their members are terrified, frightening, or worrisome of HIV/AIDS stigma attached to the epidemic. Households with PLWHA are afraid of losing the integrity or dignity of their households due to shame or humiliation from the HIV/AIDS epidemic stigma. Some of the participants as the key informants revealed that:

"The households had a bad feeling during the earlier stage of revealing the epidemic, with fear of people's reactions towards them due to the stigma attached to the pandemic in the society" (Male, 40 years old, September 9, 2019)

Another participant revealed that:

"Households with PLWHA are afraid of mentioning to the public that any member of the household is living with HIV/AIDS pandemic since some of the people in the community view HIV/AIDS as a death sentence and there is no need to come closer and by implication, we try to keep the issue to ourselves"

(Female, 32 years old, September 10, 2019)

It is pertinent to state that regarding the stigma-related issues, households with PLWHA still face challenges of stigma. Thus, households with PLWHA experience numerous forms of stigma and prejudice together with human rights abuse that is detrimental to the total well being of PLWHA and its households due to the perception and misconception on the route of transmitting HIV/AIDS and the assumptions that households with PLWHA are immoral or promiscuous in nature. Stigma is adversely affecting the interaction of households with PLWHA in the society leading to rejection, isolation, depression among others as observed as noted by Suleiman and Ayuwat (2020) that stigma and discrimination symbolizes a noteworthy challenge to an adaptive daily life for PLWHA and their households and making it unattainable for members of households with PLWHA to vigorously practice their activities essential to make life achievable and to maintain the usual active life.

It is pertinent to mention that the results of the study revealed the dimension of the stigma can be classified as internalized, community, and social-based such as fear, shame, rejection, and frustration alongside the patterns of managing the challenges of HIV/AIDS interrelated stigma. It is pertinent to state that regarding the stigma-related issues, households with PLWHA still face challenges of stigma. Thus, households with PLWHA experience numerous forms of stigma and prejudice together with human rights abuse that is detrimental to the total wellbeing of PLWHA.

This study discovered from the experience of households with PLWHA resulted in coping in the form of social isolation termed self-imposed and secrecy regarding their health situation, thus, feeling ashamed make possible the internalization of the depressing realization and culminated in more intense forms of self discrimination. This research established that the fear of stigmatization of households with PLWHA didn't fade away despite the commencement of treatment. A number of them refrained from visiting support group and prefer to get care from centres far away from their residence or engage in self-medication and alternative therapies as observed by Adeoye-Agboola et.al.(2016); UNAIDS (2017); WHO (2016) that stigma fuel the HIV/AIDS endemic by generating a culture of concealment, stillness, unawareness, culpability, embarrassment, and oppression and these forms of stigma can lead to loss of hope while it is equally noted that across the world that they avoid receiving medical from the healthcare centres due to stigma.

It is pertinent to state that regarding the stigma-related issues, households with PLWHA still face challenges of stigma. Thus, households with PLWHA experience numerous forms of stigma and prejudice together with human rights abuse that is detrimental to the total well-being of PLWHA. This research from experience described stigma as the astonishing or anticipated fear of how other people respond to households with PLWHA. It is pertinent to 
mention that households with PLWHA consider living with the epidemic as shameful and disgraceful to make the public or the community to know that any member of the household is living with the epidemic. Stigma is adversely affecting the interaction of households with PLWHA in society leading to rejection, isolation, depression among others. It is vital to state that households with PLWHA mostly feel lonely and frustrated due to the stigma related to HIV/AIDS in society.

The patterns of managing the challenges of HIV/AIDS-related stigma adopted from the experience of households with PLWHA adopted include isolation, non-disclosure, and loss of follow-up as well as migration. It is important to mention that one of the patterns of managing the challenges of HIV/AIDS-related stigma adopted from the experience of households with PLWHA adopted is isolation in order to reduce the consequences of the HIV/AIDS-related stigma. This study observed that most of the households with PLWHA are unable to communicate openly and effectively with people in the community due to the fact that they are frightened of depressing retribution concerning their previous experience on stigma related to the HIV/AIDS pandemic. It is observed that the fear of disclosure of the situation of PLWHA by themselves or their households can affect the process of treatment because they may not like to their medication in the presence of other people.

In summary, there is a social construction that PLWHA are immoral and promiscuous with negative consequences, stigma is adversely affecting the interaction of households with PLWHA in the society leading to rejection, isolation, depression, suicide. Thus, perception and misconception on the HIV/AIDS pandemic fuel the HIV/AIDS endemic by generating a culture of concealment, stillness, unawareness, culpability, embarrassment and oppression and these forms of stigma can lead to lost.

\section{Households}

The household is an important institution in all human society; it ensures the smooth running of all activities in the society while household members enjoy intimate relationship and interdependence for their basic needs (Oladeji \& Adeniji, 2015). Households can be at variance in many situations; divergences due to culture, socioeconomic class, the occurrence of labour migration among others (Gerda \& Hilde, 2011).

Masquillier et.al. (2016) assert that household as a co-residential unit and generally family based in the same way takes care of assets management and primary requirements of its members. Thus, it can be observed that the term household can be described as a single or group of people who share something such as networks, food, address as well as living accommodation in common or together. It is affirmed that most of the PLWHA in Nigeria depend on their household members for physical and emotional maintenance and the customary gender norms in Nigeria make sure that acceptably women and girls are the foremost potions for care giving tasks (Asuquo et.al. 2017).

It is essential to understand the fact that despite the fact that household vary contextually and also its headship, it is imperative to states that female-headed households and youth-headed households are on the increased and becoming more pronounced as well as becoming reality in Nigeria also despite being a patriarchal society due to migration, sickness, death, conflicts, separation or divorce of the male head of the household as confirmed by various studies such as Nigeria Demographic and Health Survey [NDHS] (2013) that one in five households are headed by a female in Nigeria and the number is expected to increase, Adelman and Peterman, (2014); Oginni et.al. (2013), that the acceptable forms of household headships and get away from the norms of a man as the customary gender to head a household are changing with the indication of more female-headed households on the increase even in the countries with strong patriarchal system that see women as subordinates to men.

The brunt of HIV/AIDS on the households with PLWHA can't be undermined due to evidence that HIV/AIDS affects the households and it has enlarged the number of orphans. It is obvious that households with PLWHA in Nigeria have experienced declining levels of income agricultural production and family assets with other impacts such as increasing numbers of widows, orphans, elderly and child-headed households (Hardee et.al. 2014; Olley et.al. 2016; Tsai \& Weiser, 2014).

Literature equally revealed that among Nigerian households when large expenditure goes towards treatment and funeral, care giving responsibilities increases and income is lost due to precipitate mortality and morbidity among the younger adult wage earners, households may be not capable to cope with the financial shock and stress (Fatusi et.al. 2016; Sirloin et.al. 2014). Consequently, it is observed that households are subjected to a numeral of social, economic, political, and demographic difficulties and also indicated that in the latest years, the HIV/AIDS epidemic has added up to the difficulties of already underprivileged or weak households due to its wide-ranging social, economic and health consequences as affirms by Alam and Mahal (2014) that health shocks whether an event of death or disease such as HIV/AIDS can significant adverse economic outcomes for households with low and middle income.

The impact of HIV/AIDS on household needs revealed or shows that the sero-positive status of their members has a great impact on the basic needs of their household owing to medical expenses and declined nature of 
income. Most of the households with PLWHA can hardly meet up their needs due to economic challenges. The households with PLWHA find it difficult to provide daily food, clothes, pay house rent, kids' school fees among others. One of the households lamented that:

\section{"My HIV/AIDS status is affecting the needs of my household members because}

I can hardly provide the basic needs, my kids are out of schools and to get the

the daily meal is a difficult thing" (Male, 40 years old, August 19, 2019)

Another household has this to say:

"The epidemic has affected my income and capitals, despite the fact that I sold my property still I could not pay my house rent, therefore, my landlord ejected me out of the house. My kids are dropped out of the schools since I cannot afford to pay their school fees" (Male, 55 years old, August 29, 2019)

In addition, studies have shown that up to 90 percent of the illness care is provided in the home (UNAIDS, 2017; WHO,2016). It is generally recognized that women and girls are the main caregivers within AIDS-affected households as supported by Asuqou et.al. (2017); Mbonu et.al. (2010); United Nations Development Programme [UNDP] 2013) that the African traditional gender norms insist on care giving as a female normative role where women and girls in the different communities become caregivers, while still needing care themselves and perhaps being HIV positive also.

\section{Educational Effects}

Education is one of the main and crucial social service sectors and it is central to the social and economic development of any nation and HIV/AIDS is a threat to this sector. It is important to mention that education as an indispensable investment for human and economic development has been badly affected by the outbreak and spread of HIV/AIDS pandemic.

It is observed the decline in school enrolments and attendance due to HIV/AIDS pandemic; some of the children have turned to caregivers or breadwinners at their tender age with much consequence on the girl child as noted by Asuquo et.al. (2017) that most of the PLWHA in Nigeria depend on their household members for physical and emotional maintenance and the customary gender norms in Nigeria make sure that acceptably women and girls are the foremost potions for care giving tasks. Thus, a number of these women and girls dropped out of work and school to offer care.

It is vital to point out that due to the impact of the pandemic on the resources of the households, some of the members of these households find it difficult to complete senior secondary schools (high schools) due to the poor economic situation of the households not able to support them financially, therefore, these children prefer to go into agriculture or some seasonal jobs as noted:

"Lack of enough and closeness of education facilities has impacted on negatively on our children because they find it difficult to cover a long distance and due to poor economic conditions of the households to support them, they can't attend schools, so some of them prefer to go into agriculture or any labour services they can render" (Male, 39 years old, September 11, 2019)

One of the households lamented that:

"My HIV/AIDS status is affecting the needs of my household members because

I can hardly provide the basic needs; my kids are out of schools...." (Male,

40 years old, August 19, 2019)

\section{Economic Effects}

The economic status of households with PLWHA in Northern Nigeria is observed to be highly pathetic because previous studies show that the economic status of households with PLWHA in relation to their lifestyles has significant implications for HIV/AIDS responses as poverty increases weakness to HIV with negative consequences on the ability of the households with PLWHA to appropriately seek for or adhere optionally to the treatment of their victims (John et.al. 2013; Mwai et.al. 2013; Smith, 2013).

It is observed that the annual estimated healthcare expense for PLWHA in Nigeria is \$58 per capita; while \$7 for HIV negative persons causing inability of infected and affected households with PLWHA to meet up with their socio-economic demands in the country and adversely consequences since the majority of the individual living with the epidemic are in their productive age and households continued to incur increased costs on livelihoods compared to their counterpart whose households members are having the negative status of the epidemic. In the 
same way, as regards the state of affairs of the livelihoods of households with PLWHA in Northern Nigeria, it is noticed that owing to their health challenges or HIV/AIDS status, per capita income losses were estimated at \$116 as compared to $\$ 21$ for the negative individuals per household (Folayan et.al. 2014; Galadanchi et.al. 2014; Gardener \& Young, 2014, Song, 2013).

Households with PLWHA go through severe hardship due to the sickness or status especially female members, who are often widows or elderly grandmothers and they usually stand the trouble of taking care of any member of the household living with the epidemic, whereas also being accountable for seeking household food and income, most of these people face challenges critical resources for livelihoods survival. For instance, in addition to the shortage of labour the women or widows experiences based on their role, they may equally lack access to credit facilities, as a long-standing limitation that has to worsen their livelihoods due to the sickness or loss of male relative who had the wide-ranging admittance to resources of economic maintenance that has always been benefiting for the entire family (Fatusi et.al. 2016; Gilson et.al. 2014; Olley et.al. 2016; Okareh et.al. 2015). In other words, the HIV/AIDS epidemic is a serious socio-economic burden to Nigeria and detrimental to sustainable development.

The impact of HIV/AIDS on household income cannot be undermined, the epidemic affects the income of households with PLWHA due to the expenses incurred such as money spent on drugs with little left for food, clothing, paying for kids' school fees among others. It was discovered that some of the households with PLWHA have to sell their property or assets in order to take care of the members of their households who are living with HIV/AIDS as noted:

"The epidemic has a great impact on the households' income. Even though there are free drugs for PLWHA, there are still opportunistic infections or diseases that are not treated freely and they are very expensive to manage. We have to borrow or sell our property to get drugs for the ailing members of the household living with HIV/AIDS epidemic" (Female, 45 years old, August 26, 2019)

Another discovery from the study revealed that:

"The epidemic is expensive to manage; the experience of my household has shown

that, no matter how buoyant any household with a member living with HIV/AIDS

the epidemic, you will still feel the impacts of the disease on your income" (Female,

30years old, August 19, 2019)

Another household has this to say:

"The epidemic has affected my income and capitals, despite the fact that I sold my property still I could not pay my house rent, therefore, my landlord ejected me out of the house. My kids are dropped out of the schools since I cannot afford to pay their school fees" (Male, 55 years old, August 29, 2019)

It is observed that the incomes of the households with PLWHA are seriously affected due to the seroprevalence status of their members. Some of them sold their property and despite that cannot afford to pay school fees and provide daily meals. The epidemic has taken most of the capital meant for the household businesses and by implication, most of the households with PLWHA are could hardly meet up with the provision of the basic needs of their household members.

However, it is important to note that in Nigeria household is the major financial organ of health care by taking care of more than health care expenditure in spite of the health policy of the country (Onwujekwe et.al.2010). In addition, studies have shown that HIV/AIDS forced households to use their savings, borrow and engage in debt crises while is also indicated that households with PLWHA in Nigeria reduced their spending to take care of the sick members of the households (Nord, 2014, Okonronkwo et.al.2015; Samson-Akpan et.al.2013) as observed below:

"The government at all level are trying but households with PLWHA are still is the major financiers of medical bills of PLWHA and it has consequences on the income of the households" (Male, 31 years old, August 27, 2019)

Another household revealed that:

"Households with PLWHA bear the main expenses of the medical of PLWHA with the serious constraint on the socio-economic conditions of the households, it drained our resources" (Female, 29 years old, August 28, 2019)

Hence, it is observed the medical expenses habitually amount to a large share of a household disposable income due to medical cost while in addition, the asymmetrical income distribution among these households and 
combined with high poverty incidence and prevalence adversely affect the poor households making some of them to results to prayers, traditional medication, self-medication or patronizing quack health practitioners with potentially tragic consequences on the existing poverty incapacitated households.

\section{Conclusion}

It is pertinent to mention that HIV/AIDS constitutes a major health and socio-economic challenge not to just the households with PLWHA in Northern Nigeria but to the entire humanity. The pandemic has been a serious threat to the social and economic interests and survival of the households with PLWHA and their members. Many lives are lost due to the pandemic. The worst affected group is young people in their productive ages and by implication affects the socio-economic development of PLWHA, their households, and society at large.

Thus, households with PLWHA experience numerous forms of stigma and prejudice together with human rights abuse that is detrimental to the total well-being of PLWHA. The dimensions of the stigma can be classified as internalized, community, and social-based. The patterns of managing the challenges of HIV/AIDS-related stigma adopted from the experience of households with PLWHA adopted include isolation, non-disclosure, and loss of follow-up as well as migration.

At the individual level, the endemic is growing and in circumstances where all forms of mitigation are missing, it can lead to the thrashing of physical power and capability to carry out basic everyday tasks, therefore, impeding the commitment of PLWHA in industrious activities, the contagion with HIV/AIDS can subsequently lead to the thrashing of household earnings and livelihoods because when one loses a job or not able to engage in incomegenerating activities and leading to the increase in the livelihood dependency, poverty as well as the loss of livelihood assets, when these resources are fatigued, relatives and community member are frequently required to come into help out and for this reason intensifying levels of dependency as noted by McCracken and Phillips (2012).

While at the household level, HIV/AIDS affects the families and leads to a rise in the figure of orphans. Households with the PLWHA epidemic have experienced declining levels of income agricultural production and family assets with other impacts such as increasing numbers of widows, orphans, elderly and child-headed households (Olley et.al. 2016). While previous studies have shown that when large expenditure goes in the direction of treatment and funeral, care giving tasks increases and earnings are lost due to precipitate mortality and morbidity among the younger adult wage earners, households may be unable to cope with the financial shock and stress (Fatusi et.al. 2016).

At the societal level, HIV/AIDS has an unfavourable brunt on the economic system, the workforce, the health care system, and all other sectors, it has a damaging impact on the education, political, and agricultural sectors while in some nations in Africa HIV/AIDS-related epidemic has reported decimating the workforce leading to socio-economic decay (Pennap et, al. 2011; Zhao et.al. 2011).

\section{Recommendations}

Based on the findings of this study, it is recommended that:

1. The government should come up with policies that can take care of and support the socio-economic activities of households with PLWHA.

2. The government needs to introduce policies and procedures for the reduction of stigma and discrimination against households with PLWHA and its members living with the epidemic.

3. Households with PLWHA need to be assisted with medication subsidies to reduce medical expenses and stress on the households' capitals.

4. Employment opportunities should be provided for households with PLWHA

5. Households with PLWHA need to be provided with soft loans and empowerment opportunities.

\section{Acknowledgments}

This paper is a part of my Ph.D. Dissertation titled "Livelihoods of Households with People Living With HIV/AIDS in Northern Nigeria". We would like to thank Research and Training Centre for Enhancing Quality of Life of Working-Age People, Faculty of Nursing, Khon Kaen University, Khon Kaen, Thailand and Labour, and International Migration Centre, Khon Kaen University, Khon Kaen, Thailand for their support.

The researchers would also like to thank all the key respondents who provided useful information for this research. We would also like to thank the Khon Kaen University Ethics Committee in Human Research based on 
the Declaration of Helsinki and the ICH Good Clinical Practice Guidelines for granting this research approval with reference no HE623051.

\section{Corresponding Author}

Corresponding Author: Ph.D., Professor, Labour, and International Migration Service Centre, Department of Social Sciences, Division of Sociology and Anthropology, Khon Kaen University, Khon Kaen, Thailand Email: dusayu@kku.ac.th

\section{References}

Adelman, S. and Peterman, A. (2014) Resettlement and Gender Dimensions of Land Rights in Post-Conflict Northern Uganda. World Development, 64, 583-596

Adeoye-Agboola, D.I., Evans, H., Hewson, D. and Pappas, Y. (2016) Factors Influencing HIV Disclosure among People Living with HIV/AIDS in Nigeria: A Systematic Review Using Narrative Synthesis and Metaanalysis. www.elsevier.com/Puhe

Alam, K. and Mahal, A. (2014) Economic Impacts of Health Shocks on Households in Low and MiddleIncome Countries: A Review of the Literature. Globalization and Health 10:21

Asuquo, E.F., Etowa, J.B. and Akpan, M.I. (2017) Assessing Women Care Giving Role toPeople Living with HIV/AIDS in Nigeria. SAGE Open Journal

Ayuwat, D. and Chamaratana, T. (2014) The Role of Labour Broker Networks in Setting the Price of Working Abroad for Thai Migrant Workers. Asia-Pacific Population Journal, 27(1), 1-28

Fatusi, A., Bamidele, M.A., Sowande, A.O. and Pearson, J (2016) Baseline Assessment of Infection and Control and Health Care Waste Management in Selected LGAS in Akwa-Ibom, Cross River, and River States. Arlington. VA: Strengthening High Impact Interventions for an AIDS-Free Generation (AIDS-free) Project

Folayan, M.O. Brown, B. Odetoyinbo, M. and Harirson A (2014) Rape in Nigeria: A Silent Epidemic among Adolescent with Implications for HIV Infection. Glo Health Action

Frantz, R.G. and Murenzi, A. (2014) The Physical Activity Levels among PLWHA Receiving High Actively Antiretroviral Therapy in Rwanda. Sahara Journal, 10, 13-18

Galadanchi, H. Gaya, S.A. Abubakar, S. and Iliyasu, Z (2014) Decentralization of Prevention of Mother-to-Child Transmission Services in Nigeria: Aminu Kano Teaching Hospital's $\quad$ Experience. 1(2): 64-69

Gardner, E.M. and Young, B. (2014) The HIV Care Cascade Through Time. The Lancet Infectious Diseases. 14(1): 5.doi: 10:1016/S 1473-3099 PMID: 24076276

Gerda, J.C., and Hilde, T. (2011) Defining and Using the Concept of Household: ASystematic Review. International Journal of Consumer Studies

Gilson, L., Elloker, S., Olckers, P. and Lehmann U. (2014) Advancing the Application of Systems Thinking in Health: South Africa Examples of a Leadership of Sense-Making Healthcare. Health Res Policy Syst. 12(30), 10,1186

Goffman, E. (1963) Stigma: Notes on the Management of Spoiled Identity. New York NY:Simon and Schuster

Hardee, K., Gay, J., Croce-Galis, M. and Peltz, A. (2014) Strengthening the Enabling Environment of Women and Girls: What is the Evidence from Social and Structural Approaches in the HIV Response? J Int. AIDS Soc. 17(1), 18619

John, C, Okolo, and S.N. Isichiei. C (2013) Sexual Behaviour and HIV Infection among Adolescent in Secondary Schools in Jos, Nigeria. J Paedrt. 41(2): 86-89

Levien, M (2015) Social Capital as Obstacle to Development: Brokering Land, Norms and Trust in Rural India. World Development, 74, 77-92

Link, B.G. and Phelan, J.C. (2001) Conceptualizing Stigma. Annual Rev. Sociol: 27: 363-85

Masquillier, C. et.al. (2016) HIV/AID Competent Households: Interaction between a Health-Enabling Environment and Community Based Treatment Adherence Support for PeopleLiving with HIV/AIDS in South Africa. PluS ONE 11(3): e0151379. Dio: 10. 1371/jpurnal.pone.0151379

Mbonu, N.C., Borne, B.V. and De Vries, N.K. (2010) Gender-Related Power Differences,Beliefs and Reactions towards PLWHA: An Urban Study in Nigeria. BMC Public Health 10:334

McCracken, K. and Phillips, D.R. (2012) Global Health: An Introduction to Current Trends: Routledge, New York

Mwai, G.W. Mburu, G. Torpey, K. Frost, P. Ford, N. and Seeley, J (2013) Role and Outcomes of Community Health Workers in HIV Care in Sub-Saharan African: A Systematic Review. Journal of the International AIDS Society, 16 (1)

National Agency for the Control of AIDS [NACA] (2015) Nigeria_GARPR_2015_Report. NACA Nigeria

National HIV/AIDS Strategic Framework 2017-2021

Nigeria Demographic and Health Survey [NDHS] (2013) National Population Commission, Abuja, Nigeria 
Nord, M. (2014) What Have We Learned from Two Decades on Household Food Security? Public Health Nutrition, 17(01), 2, 4

Oginni, A., Ahonsi, B. and Ukwuije, F. (2013) Are Female-Headed Households Typically Poorer than MaleHeaded Households in Nigeria? The Journal of Socio-Economic, 45 (132-137)

Okareh, O.T, Akpa, O.M. Okunlola, J.O and Okoror, T.A. (2015) Management of Conflicts Arising from Disclosure of HIV Status among Married Women in South West Nigeria. Health Care for Women International Vol. 36 No 2 Pg 149-160

Okoronkwo, I. et.al. (2015) Assessing Self Care Practices of People Living with HIV/AIDS Attending Antiretroviral Clinic Kafanchan, Kaduna State, Nigeria. J.AIDS Clin.Res. 6.12

Oladeji, M.O. and Adeniji, D.O. (2015) Family Security; An Approach to Achieving Household Livelihood in Nigeria. IOSR Journal of Humanities and Social Sciences, Vol.20, Issue 9 Ver.11, Pg 41-44

Olley, B.O., Ogunde, M.J., Oso, P.O. and Ishola, A. (2016) HIV-Related Stigma and Self Discourse. The Mediating and Moderating Role of Anticipated Discrimination among PLWHA in Akure, Nigeria. AIDS Care-Psychological and Socio-Medical Aspects of AIDS/HIV, Vol 28, No 6, Pg 726-73

Onwuekwe, O. E. Uzochukwu, B.S.C. Obikeze, E.N., Okoronkwo, I, Ochanma O.G. Onoka, C.A.et.al. (2010) Investigating Determinants of Out of Pocket Spending and Strategies for Coping with Payment for Healthcare in South East, Nigeria. BMC Health Services Research, Vol.10, No1, Pg 67-76

Parker, R., and Aggelton, P. (2003) HIV/AIDS-Related Stigma and Discrimination: A Conceptual Framework and Implications for Action. Social Sciences and Medicine: 57; 13-24 [Pub Med]

Pennap, G.R., Chaanda, M. and Ezirike, L. (2011) A Review of the Impact of HIV/AIDS on Education and the Workforce and Workplace: The African Experience. The Social Sciences, Vol.6, No.2, Pg. 164-168

Samson-Akpan, P.E., Ojong, I.N., Ella, R. and Edet, O.B (2013) Quality of Life of People Living with HIV/AIDS in Cross River, Nigeria. International Journal of Medicine and Biomedical Research, Vol.2, Issue $3, \operatorname{Pg} 207-212$

Sirotin, N., Hoover, D.R., Shi, Q., Anasto, K. and Weiser, S.D. (2014) Food Insecurity with Hunger is Associated with Obesity among HIV-Infected and at Risk Women in Bronx, NY. PloS one, 9(8),e 105957

Smith, M. (2013) The End of HIV? The Cure Demands Social Change (Social Inequality) Harvard International Review, 34(4) 6-7Song, L. (2013) Social Capital and Health in Medical Sociology on the Move. Netherland. Springer, Pg 233-257

Suleiman, M.S. and Ayuwat, D. (2020) A Qualitative Study of Stigma Experience by Households with People Living With HIV/AIDS in Kaduna State, Nigeria. Systematic Reviews in Pharmacy, 11(6)1320-1328 doi:10:31838/srp.2020.6.192

The Joint United Nations Programme on HIV/AIDS [UNAIDS] (2014) Global AIDS Response Progress Reporting. http://www.unaids.org.media.asset. Accessed on 7th February 2018 (2016) Global AIDS Update. http://www.unaids.org.media.asset Accessed on 9th February 2018 (2017) Prevention Gap Report. Geneva

Tsai, A.C., and Welser, S.D. (2014) Population-Based Study of Food Insecurity and HIVTransmission Risk Behaviours and Symptoms of Sexually Transmitted Infections among Linked Couples in Nepal. AIDS and Behaviour, 18(11), 2187-2197

United Nations Development Programme [UNDP] (2013) The MDG Report 2013: Assessing Progress in Africa towards the Millennium Development Goals. http://www.undp.org./content/dam/uganda/docs/ Africa MDG report2013summaryen.pdf

World Health Organization [WHO] (2015) Global Tuberculosis Report 2015http://www.who.int/publications/enRetrieved 17th July 2018 (2016) Global Health Estimates 2015 Deaths by Cause, Age, Sex by Country and by Region, 200-2015. Geneva

Zhao, J. Li, X. Barnett, D. Lin, X. Fang, X, Zhao G. et,al. (2011) Parental Loss, Trusting Relationship with Different Caregivers and Psychological Adjustment among Children Affected by AIDS in China. Psychology, Health and Medicine, Vol.16, No.4, Pg. 437- 449 